\title{
Characterization of MALS/Velis-1, -2, and -3: a Family of Mammalian LIN-7 Homologs Enriched at Brain Synapses in Association with the Postsynaptic Density-95/NMDA Receptor Postsynaptic Complex
}

\author{
Kiwon Jo, ${ }^{1}$ Rachel Derin, ${ }^{2}$ Min $\mathrm{Li}^{2}{ }^{2}$ and David S. Bredt ${ }^{1}$ \\ ${ }^{1}$ Department of Physiology, School of Medicine, University of California at San Francisco, San Francisco, California \\ 94143-0444, and 2Department of Physiology, Johns Hopkins University School of Medicine, Baltimore, Maryland 21205
}

Protein assembly at the postsynaptic density (PSD) of neuronal synapses is mediated in part by protein interactions with PSD95/discs large/zona occludens-1 (PDZ) motifs. Here, we identify MALS-1, -2, -3, a family of small synaptic proteins containing little more than a single PDZ domain. MALS-1, -2 , and -3 are mammalian homologs LIN-7, a Caenorhabditis elegans protein essential for vulval development. In contrast to functions for LIN-7 in epithelial cells, MALS-1 and -2 are selectively expressed in specific neuronal populations in brain and are enriched in PSD fractions. In cultured hippocampal neurons, MALS proteins are clustered together with PSD-95 and NMDA type glutamate receptors, consistent with a postsynaptic localization for MALS proteins. Immunoprecipitation and affinity chromatography studies readily identify association of MALS with PSD-95 and an NMDA receptor subunit. The PDZ domain of MALS selectively binds to peptides terminating in E-T/S-R/ $\mathrm{X}-\mathrm{V} / \mathrm{I} / \mathrm{L}$, which corresponds to the $\mathrm{C}$ terminus of NMDA type 2 receptors and numerous other ion channels at the PSD. This work suggests a role for MALS proteins in regulating recruitment of neurotransmitter receptors to the PSD.

Key words: MALS; PDZ; LIN-7; PSD-95; NMDA receptor; postsynaptic density; C. elegans
Rapid and reliable synaptic transmission requires that neurotransmitter receptors and associated downstream signaling molecules are clustered together beneath the postsynaptic membrane (Sheng, 1996; Kornau et al., 1997; Craven and Bredt, 1998). Mechanisms for organizing postsynaptic signal transduction cascades at excitatory synapses in brain are not yet clear. Valuable clues have come from studies of the postsynaptic density (PSD), an electron-dense cytoskeletal structure enriched with neurotransmitter receptors and associated transduction machinery (Cho et al., 1992). Assembly of some components of the PSD appears to be mediated by PSD-95/synapse-associated protein-90 (SAP-90) and related membrane-associated guanylate kinase (MAGUK) proteins (Kistner et al., 1993; Sheng, 1996; Kornau et al., 1997; Craven and Bredt, 1998). PSD-95 is anchored to synaptic membranes by N-terminal palmitoylation (Topinka and Bredt, 1998) and contains three PSD-95/discs large/zona occludens-1 (PDZ) protein-protein interaction motifs that directly bind to NMDA type glutamate receptors (Kornau et al., 1995) and to certain downstream signaling enzymes, including neuronal nitric oxide synthase (nNOS) (Brenman et al., 1996; Craven and Bredt, 1998).

PDZ domains are protein interaction domains that often bind

\footnotetext{
Received Jan. 21, 1999; revised March 10, 1999; accepted March 12, 1999.

This work was supported by grants (to D.S.B.) from The EJLB Foundation, the National Association for Research on Schizophrenia and Depression, the Beckman and Culpeper Foundations, and National Institutes of Health (R01, GM36017). K.J. is supported by a postdoctoral fellowship from the American Heart Association. M.L. is an American Heart Association Pfizer awardee and was supported by a grant from National Institutes of Health (NS33324). We thank Dr. Bonnie Firestein for preparing hippocampal cultures and performing subcellular fractionation.

Correspondence should be addressed to David S. Bredt, University of California at San Francisco, School of Medicine, 513 Parnassus Avenue, San Francisco, CA 94143-0444.

Copyright (C) 1999 Society for Neuroscience $\quad 0270-6474 / 99 / 194189-11 \$ 05.00 / 0$
}

to the very C terminus of protein targets (Doyle et al., 1996; Songyang et al., 1997). This binding is primarily determined by the final four amino acids of the protein target; however, upstream sequences in the target are also critically involved. Evidence that PDZ proteins mediate receptor localization at synapses and other cell-cell junctions derives from studies of invertebrates. Mutation of Discs-Large tumor suppressor protein, a Drosophila MAGUK related to PSD-95 (Woods and Bryant, 1991), causes abnormalities of synaptic structure (Lahey et al., 1994), including disruption of Shaker $\mathrm{K}^{+}$channel clustering at the larval neuromuscular junction (Tejedor et al., 1997). In Caenorhabditis elegans, studies of vulval development have implicated several PDZ proteins in polarized receptor localization to the basolateral membrane of vulval precursor cells. In this pathway, three PDZ-containing proteins mediate basolateral localization of LET-23, a receptor tyrosine kinase essential for vulval development (Simske et al., 1996). The three PDZ proteins are LIN-2, a MAGUK protein similar to mammalian CASK (Hata et al., 1996; Hoskins et al., 1996); LIN-10, a protein containing two PDZ domains similar to mammalian Mint/X11 (Okamoto and Südhof, 1997; Kaech et al., 1998); and LIN-7, a small protein containing little more than a single PDZ domain (Simske et al., 1996). Molecular mechanisms by which LIN-2, LIN-7, and LIN-10 anchor LET-23 are uncertain, but LIN-7 directly binds LET-23 and associates with it along the basolateral membrane of vulval precursor cells (Simske et al., 1996).

Because synaptic junctions bear certain similarities with epithelial tight junctions (Cho et al., 1992), we wondered whether mammalian homologs of LIN-7 might exist and play a role in synaptic function. Here, we identify MALS-1, -2, -3 (for mammalian LIN-seven protein), which are identical to the Velis that were 


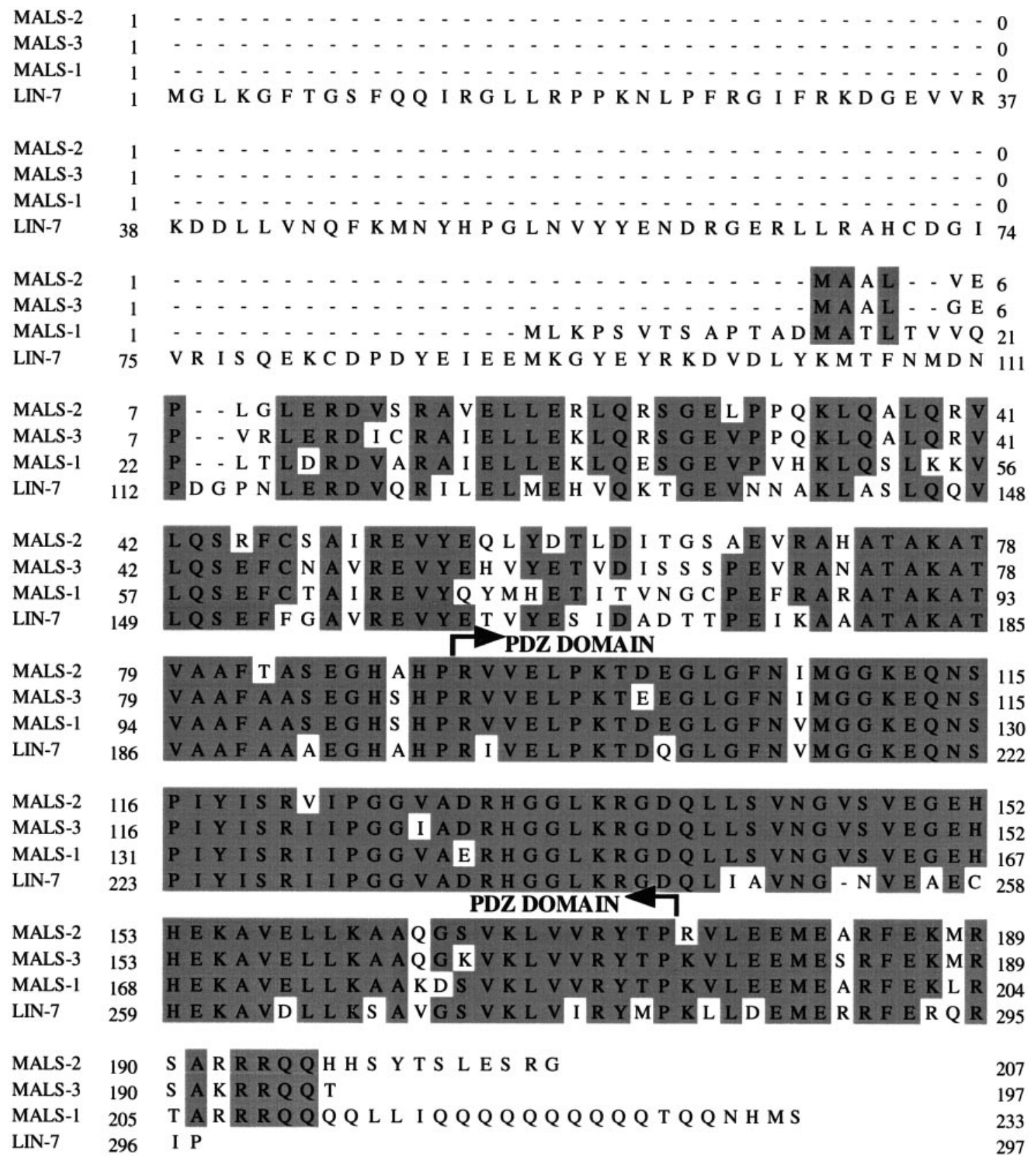

Figure 1. Sequence alignment of MALS-1, -2, and -3 with LIN-7. Sequences are shown in single letter amino acid code and are aligned for maximal homology with the $C$. elegans LIN-7 protein. Residues present in a majority of the sequences are shaded gray. Arrowheads designate the PDZ domains. (GenBank accession numbers for cDNAs encoding MALS-1, -2, and -3 are AA405216, W75523, and AA462021, respectively.)

reported (Butz et al., 1998) while this work was under review. MALS are homologous to C. elegans LIN-7 (Simske et al., 1996), and each contains little more than a single PDZ domain. MALS-1 and -2 are neuron specific, whereas MALS-3 is also expressed in peripheral tissues. MALS-1 and -2 are highly enriched in postsynaptic density preparations in association with PSD-95/NMDA receptor complexes. Affinity panning indicates that the PDZ domain of MALS-2 preferentially binds peptides terminating E-T/S-R/X$\mathrm{I} / \mathrm{V} / \mathrm{L}$, which resembles the $\mathrm{C}$ terminus of type 2 NMDA receptors. These results suggest a possible role for MALS proteins in regulating receptor clustering associated with the PSD-95 protein complex.

\section{MATERIALS AND METHODS}

Northern blotting. Multiple tissue rat Northern blots (RB no. 1002) were purchased from Origene (Rockville, MD). Blots were hybridized with random primed $\left[{ }^{32} \mathrm{P}\right]$-labeled probes $\left(10^{7} \mathrm{cpm} / \mu \mathrm{g}\right)$, which were generated using the $3^{\prime}$ UTR of MALS cDNAs as templates. Hybridizations were done in Express-Hyb buffer at $68^{\circ} \mathrm{C}$ for $1 \mathrm{hr}$ as specified by the manufacturer (Clontech, Palo Alto, CA). After hybridization, blots were washed twice at room temperature for $20 \mathrm{~min}$ at low stringency $(2 \times$ SSC and $0.1 \% \mathrm{SDS})$ and twice at $50^{\circ} \mathrm{C}$ for $20 \mathrm{~min}$ at high stringency $(0.1 \times$ SSC and $0.1 \%$ SDS). The blots were exposed overnight to $\mathrm{x}$-ray film at $-80^{\circ} \mathrm{C}$.

$D N A$ constructs. Glutathione- $S$-transferase (GST) fusion constructs were prepared by PCR into pGEX4T vector (Pharmacia Biotech, Uppsala, Sweden) and confirmed by sequencing. The following fusion pro- 


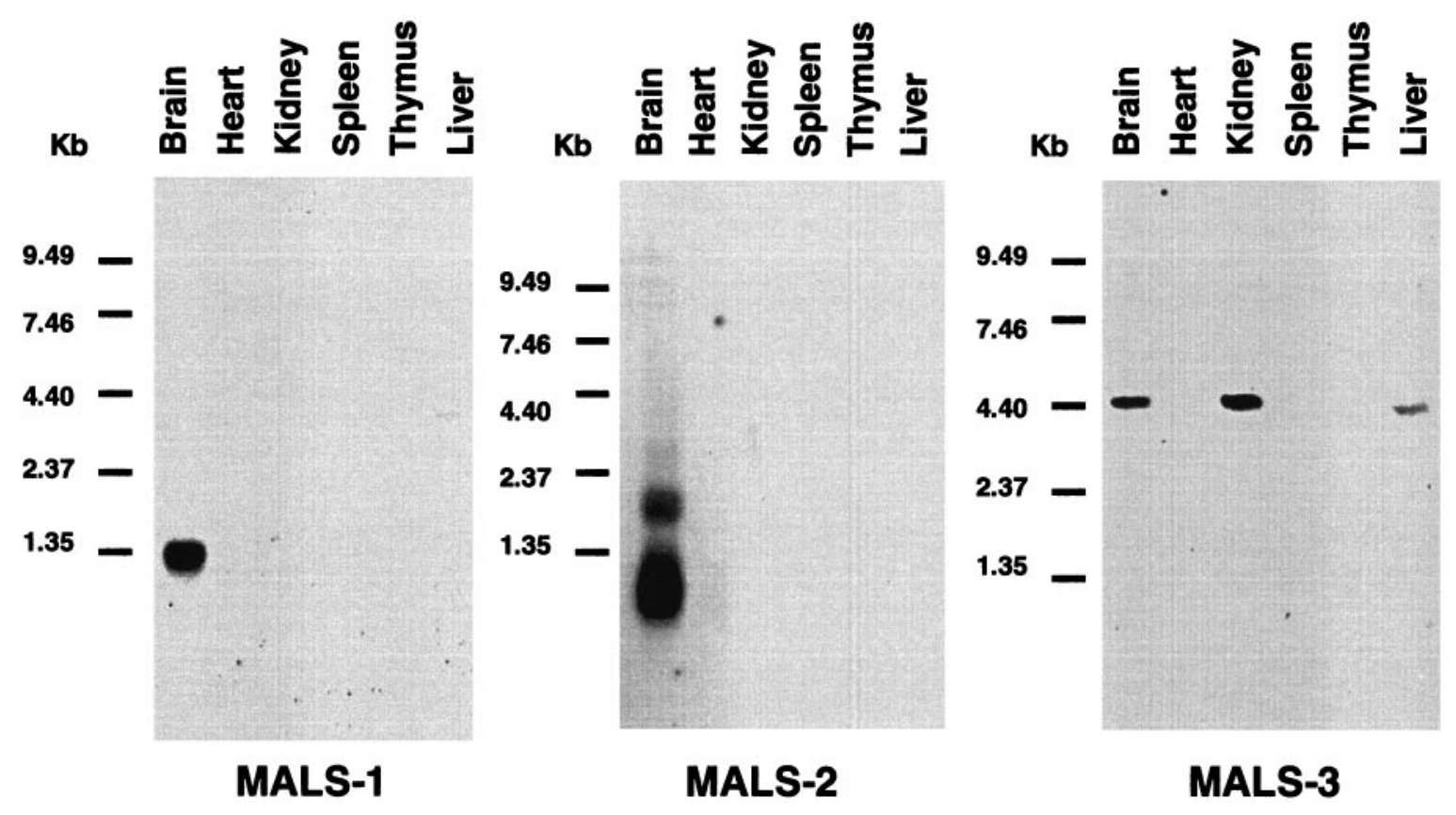

Figure 2. Tissue distribution of MALS-1, -2 , and -3 mRNA. Northern blots of poly $\left(\mathrm{A}^{+}\right)$RNA from various rat tissues $(2 \mu \mathrm{g} /$ lane $)$ hybridized with $\left[{ }^{32} \mathrm{P}\right]-$ labeled cDNA probes to MALS-1, -2 , and -3 .

teins were constructed: GST:MALS-1(N81), residues 1-81; GST: MALS-2(N70), residues 1-70; GST:MALS-2(total), residues 1-207; GST:MALS-2(PDZ), residues 92-207; GST:MALS-2(19-207), residues 19-207, GST:NR2B(C9), C-terminal nine amino acids. For expression in COS7 cells, the full-length coding regions of MALS-1, -2 , and -3 were subcloned into mammalian expression vector pcDNA3 (Invitrogen, Carlsbad, CA), NMDA receptor subunit 2B (NR2B) into pRK5 (Genentech, San Francisco, CA), PSD-95 into pGW1-CMV (British Biotech, Oxford, UK), and MALS-2 into pEGFP-c2 (Clontech).

Antisera. GST:MALS-2(19-207) and GST:MALS-1(1-81) were expressed and purified from Escherichia coli as described previously (Brenman et al., 1996). Rabbits were immunized with the MALS-2 fusion protein, and guinea pigs were immunized with the MALS-1 fusion protein. Antigens were emulsified in complete and incomplete Freund's adjuvant. Serum bleeds were evaluated by ELISA. For affinity purification of MALS-2 antibody, MALS-2 antiserum was precipitated with
$40 \%$ ammonium sulfate, resuspended with $500 \mathrm{~mm}$ Tris- $\mathrm{HCl}, \mathrm{pH} 7.5$, dialyzed in $10 \mathrm{~mm}$ Tris- $\mathrm{HCl}, \mathrm{pH} 7.5$, and applied to a column of GST protein conjugated to Affigel-10 (Bio-Rad, Hercules, CA). The flowthrough was collected and reapplied to a column of GST:MALS-2 fusion protein immobilized to Affigel-10. The column was washed with $20 \mathrm{vol}$ of buffer containing $10 \mathrm{~mm}$ Tris-HCl, $\mathrm{pH} \mathrm{7.5}$, and $500 \mathrm{~mm} \mathrm{NaCl}$. The MALS-2 antibody was eluted with 1 bed volume of $100 \mathrm{~mm}$ glycine, $\mathrm{pH}$ 2.5. Antibodies to $\mathrm{K}_{\mathrm{v}} 1.4$ (a gift from Lily Jan), PSD-95 (Affinity BioReagents, Golden, CO), erbB4 (NeoMarkers, Fremont, CA), synaptophysin (Sigma, St. Louis, MO), NR2B (Transduction Labs, Lexington, KY), GST (Santa Cruz Biotechnology, Santa Cruz, CA), neurofilament-H (Zymed, San Francisco, CA), and NR1 (PharMingen, San Diego, CA) were used as specified by the supplier.

Western blot analysis and immunohistochemistry. For Western blotting, tissues were homogenized in $20 \mathrm{vol}(\mathrm{w} / \mathrm{v})$ of TEE ( $25 \mathrm{~mm}$ Tris- $\mathrm{HCl}, \mathrm{pH}$ 7.5, $1 \mathrm{~mm}$ EDTA, and $1 \mathrm{~mm}$ EGTA) containing $1 \mathrm{~mm}$ phenylmethylsul-
A.

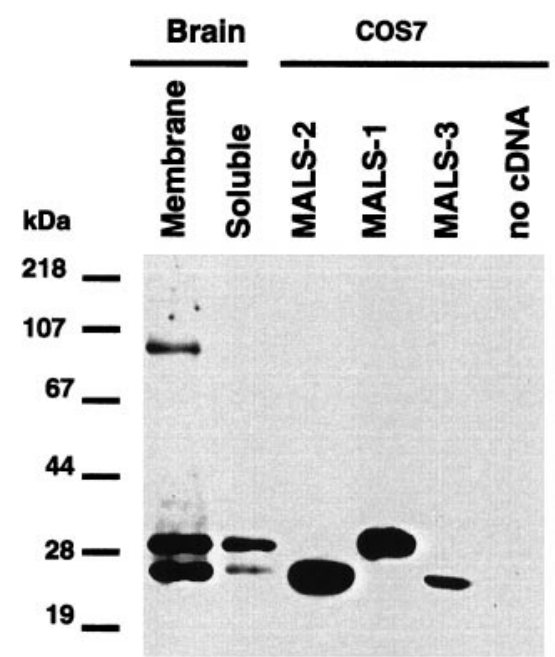

IB: $\alpha$ MALS
B.

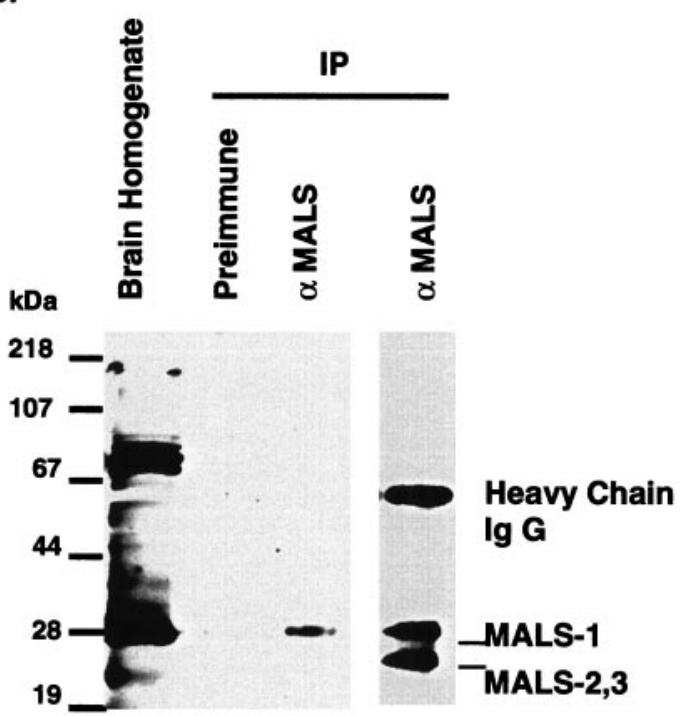

IB: $\alpha$ MALS- $1 \quad$ IB: $\alpha$ MALS
Figure 3. Identification of MALS proteins in brain. $A$, Western blotting of rat brain membrane and soluble fractions $(15 \mu \mathrm{g} /$ lane $)$ with an affinity-purified MALS antibody demonstrates that MALS proteins are present in brain. The $25 \mathrm{kDa}$ MALS band is primarily membraneassociated, and the $30 \mathrm{kDa}$ MALS band is equally distributed in membrane and soluble fractions. MALS-1, -2, and -3 protein expressed in COS7 cells (3 $\mu \mathrm{g} / \mathrm{lane})$ comigrated with 30 (MALS-1) and 25 (MALS-2.3) kDa bands. $B$, Crude brain homogenate and brain extracts immunoprecipitated with preimmune serum or affinity-purified MALS antibody were immunoblotted with antiserum to MALS-1. 


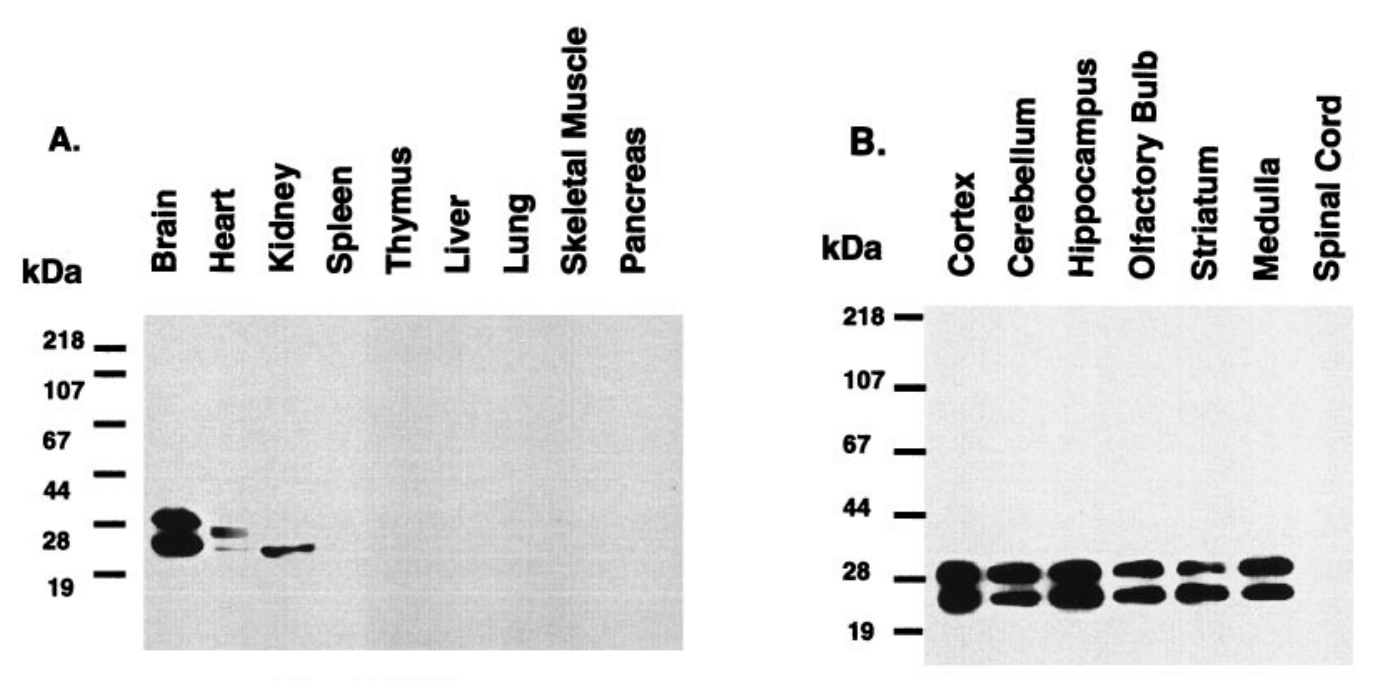

Figure 4. MALS proteins are selectively enriched in brain. $A$, WestIB: $\alpha$ MALS ern blotting of rat tissue homogenates $(15 \mu \mathrm{g} /$ lane $)$ probed with an affinity-purified MALS antibody demonstrates that MALS are enriched in brain. $B$, An immunoblot of extracts from rat brain regions (15 $\mu \mathrm{g} /$ lane) probed with the affinity-purified MALS antibody shows ubiquitous expression of MALS in rat brain. $C$, A sagittal section of rat brain was processed for MALS immunohistochemistry. This dark-field image suggests a neuronal localization for MALS and shows that highest levels of MALS expression occur in cerebellum $(C B)$, cerebral cortex $(C X)$, hippocampus $(H P)$, striatum $(S T)$, thalamus $(T)$, and inferior colliculi (IC). SC, Superior colliculi; $H$, hypothalamus.

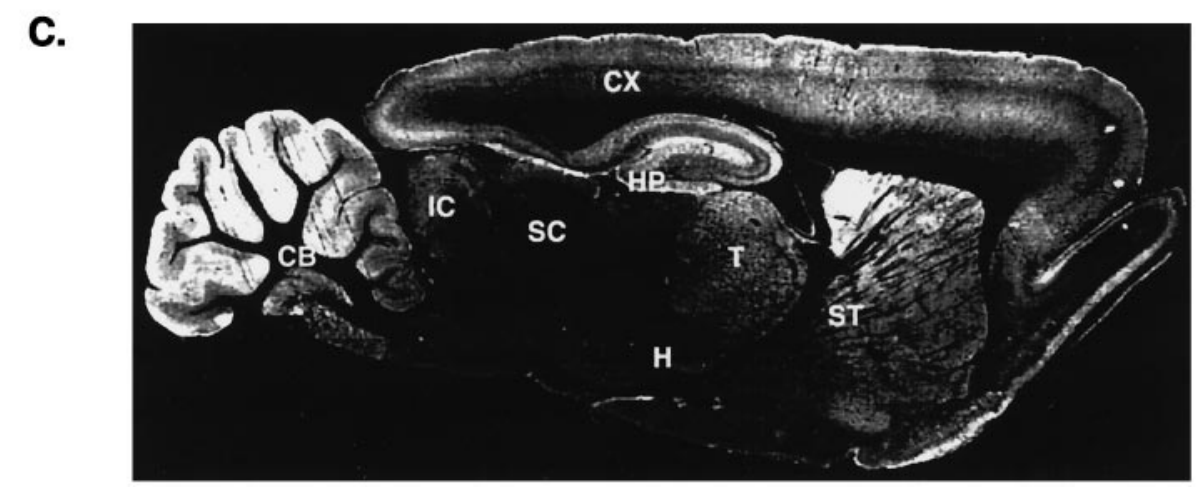

fonylfluoride (PMSF). Proteins were separated by $10 \%$ SDS-PAGE, and gels were transferred to polyvinylidine difluoride (Millipore, Bedford, MA) membranes, which were blocked with $3 \%$ BSA. Western blots were developed using enhanced chemiluminescence as described previously (Brenman et al., 1996). Protein concentration was determined by Bradford assay (Bio-Rad). For immunohistochemistry, rats were perfused with $4 \%$ freshly depolymerized paraformaldehyde in $0.1 \mathrm{M}$ phosphate buffer. Brains were removed and cryoprotected overnight in $20 \%$ sucrose, and free-floating sections $(40 \mu \mathrm{m})$ were cut on a sliding microtome. Immunohistochemical staining used an avidin-biotin-peroxidase system (ABC Elite; Vector Laboratories, Burlingame, CA) according to the manufacturer's instructions. Peroxidase staining was developed using 3,3'-diaminobenzidine as the chromogen.

Subcellular fractionation. Subcellular fractions of rat cerebral cortex were prepared by differential centrifugation as described previously ( $\mathrm{Li}$ et al., 1996). Rat cerebral cortices were homogenized in buffer containing $320 \mathrm{~mm}$ sucrose and $4 \mathrm{~mm}$ HEPES-NaOH, $\mathrm{pH}$ 7.3. The homogenate was centrifuged for $10 \mathrm{~min}$ at $1000 \times g$ to produce a pellet $(\mathrm{P} 1$, crude nuclear fraction). The supernatant (S1) was centrif uged at $12,000 \times g$ for $15 \mathrm{~min}$ to produce a pellet (P2) and supernatant (S2). The pellet was resuspended in the original volume of homogenization buffer and centrif uged for $15 \mathrm{~min}$ at $13,000 \times g$ to yield the crude synaptosomal fraction $\left(\mathrm{P} 2^{\prime}\right)$. The P2' fraction was resuspended in homogenization buffer and hypotonically lysed by addition of $9 \mathrm{vol}$ of ice-cold water and homogenized in a glass Teflon homogenizer (three strokes). The lysate was brought to 4 mM HEPES by addition of 1 м HEPES, $\mathrm{pH} 7.3$, and centrif uged for 20 min at $33,000 \times g$ to produce the lysate heavy membrane pellet (LP1) and lysate supernatant (LS1). The LS1 fraction was then centrifuged at $260,000 \times g$ for $2 \mathrm{hr}$ to give a crude synaptosomal vesicle pellet (LP2) and a cytosolic synaptosomal supernatant (LS2). In a separate procedure, synaptosomes and PSD fractions were prepared from five rat cerebral cortices as described previously (Cho et al., 1992). Briefly, the synaptosome fraction purified by discontinuous sucrose density gradient centrifugation was extracted once or twice with ice-cold $0.5 \%$ Triton X-100 and then centrifuged to obtain the PSD (one Triton) and PSD (two Triton) pellets. The PSD (one Triton) pellet was separately extracted with $3 \%$ Sarcosyl and centrifuged to obtain the PSD (one Triton + Sarcosyl) pellet.

Transfection of COS7 cells. COS7 cells were grown in DMEM containing $10 \%$ fetal bovine serum, penicillin, streptomycin, and L-glutamine in $5 \% \mathrm{CO}_{2}$. Cells were transiently transfected with cDNA constructs of full-length PSD-95, NR2B, and MALS proteins in mammalian expression vectors using Lipofectamine reagent according to the manufacturer's protocol (Life Technologies, Gaithersburg, MD).

Immunoprecipitation. Rat cerebral cortices were homogenized in $20 \mathrm{vol}$ (w/v) of deoxycholate (DOC) buffer (containing $25 \mathrm{~mm}$ Tris-HCl, $\mathrm{pH} 7.5$, $150 \mathrm{~mm} \mathrm{NaCl}, 1 \mathrm{~mm}$ EDTA, $1 \mathrm{~mm}$ EGTA, $1 \mathrm{~mm}$ PMSF, $2 \mathrm{~mm}$ $\beta$-mercaptoethanol, $50 \mathrm{~mm} \mathrm{NaF}, 1 \mathrm{~mm}$ sodium vanadate, and $20 \mathrm{~mm}$ $\mathrm{ZnCl}_{2}$ ) and centrifuged at $100,000 \times g$ for $30 \mathrm{~min}$ to yield a membrane fraction. The membranes were resuspended in DOC buffer supplemented with $1 \%$ sodium deoxycholate and solubilized for $2 \mathrm{hr}$ at $4^{\circ} \mathrm{C}$, Triton $\mathrm{X}-100$ was added to $1 \%$, and the preparation was cleared by centrifugation at $100,000 \times g$ for $30 \mathrm{~min}$. Affinity-purified antibody $(5 \mu \mathrm{g})$ was added to $1 \mathrm{ml}$ of solubilized membrane extract $(500 \mu \mathrm{g} / \mathrm{ml})$. After a 60 min incubation on ice, $50 \mu \mathrm{l}$ of protein A Sepharose (1:1 slurry in TEE buffer) was added to precipitate antibodies. The protein A pellet was washed three times with TEE buffer containing $1 \%$ Triton X-100 and 150 


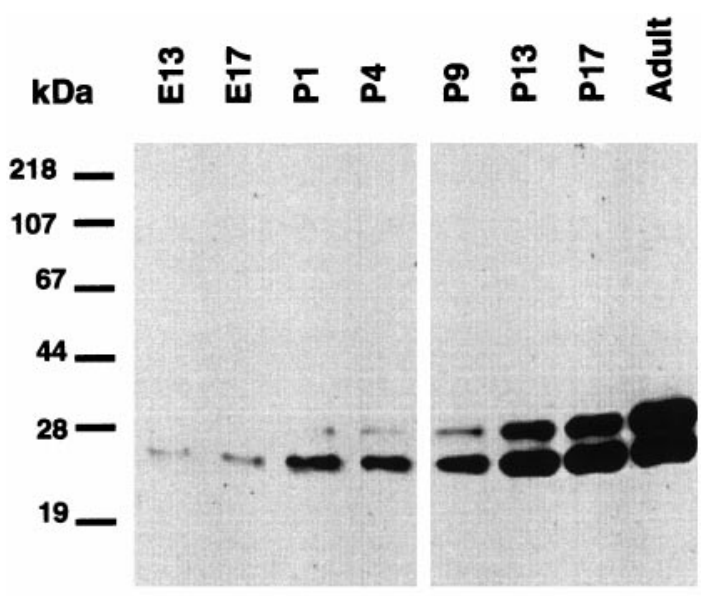

IB: $\alpha$ MALS

Figure 5. MALS protein expression progressively increases during brain development. Homogenates from rat brain at various developmental stages $(15 \mu \mathrm{g} /$ lane) were immunoblotted with the affinity-purified MALS antibody. Embryonic $(E)$ and postnatal $(P)$ days are indicated. $\mathrm{mm} \mathrm{NaCl}$. Immunoprecipitated proteins were denatured with loading buffer and resolved by $10 \%$ SDS-PAGE.

GST fusion protein affinity chromatography. GST fusion proteins were expressed in Escherichia coli and purified on glutathione Sepharose beads as described previously (Brenman et al., 1995). For "pull-down" assay, transfected COS7 cells or dissected cerebral cortices were homogenized in $20 \mathrm{vol}(\mathrm{w} / \mathrm{v})$ of DOC buffer and solubilized as described above. Solubilized membranes were incubated with control (GST) or GST fusion protein beads for $1 \mathrm{hr}$. Samples were loaded into disposable columns, which were washed with 50 vol of buffer containing $1 \%$ Triton $\mathrm{X}-100$ and $150 \mathrm{~mm} \mathrm{NaCl}$ and protein eluted with loading buffer.

Neuronal cell culture and immunocytochemistry. Cultures of embryonic day 18 (E18) rat hippocampal neurons were grown as described previously (Apperson et al., 1996). After $14 \mathrm{~d}$ in culture, the neurons were fixed and stained with affinity-purified antibodies as described previously (Apperson et al., 1996).

Affinity panning. A fusion protein GST:MALS-2(19-207) was used for affinity panning of a random LacI-based peptide library. The procedures for PDZ domain panning and ELISA detection have been described previously in detail (Stricker et al., 1997). Briefly, a pool of oligonucleotides encoding 15 random amino acids was cloned in frame $\mathrm{C}$ terminal to LacI coding sequences. Protein expression from each plasmid of the library yielded a LacI fusion with a distinct peptide sequence. The recombinant LacI binds to lac $O$ sites present on the same plasmid yielding LacI-plasmid complexes that were purified from E. coli. Affinity panning selects peptides that interact with target GST:MALS-2. The bound plasmid DNAs were specifically separated from the LacI proteins by addition of isopropyl- $\beta$-D-thiogalactopyranoside. The recovered plasmids were retransformed, amplified, and used for subsequent rounds of

A.

\section{H P1 S1 P2 P2' LP1 LP2 LS2}

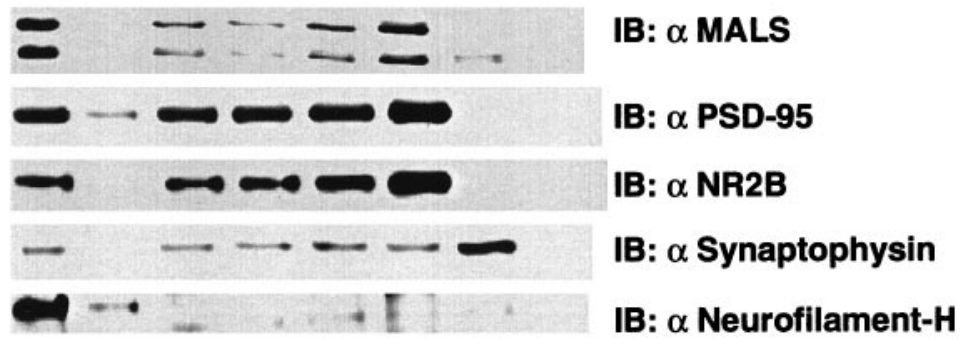

B.

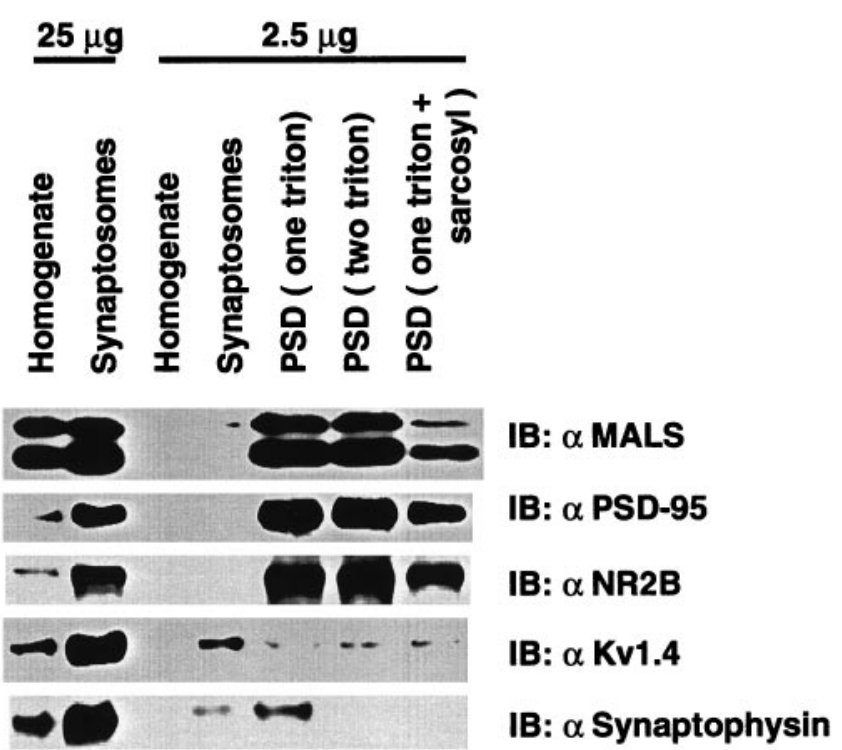

Figure 6. MALS proteins are enriched in PSD fractions. $A$, Subcellular fractions of rat cerebral cortex were prepared by differential centrifugation. Aliquots from this fractionation were probed by Western blotting with MALS antibody. Antibodies against PSD-95 and NR2B, synaptophysin and neurofilament-H, were used as controls for postsynaptic proteins, a synaptic vesicle protein and a nonsynaptic protein, respectively. Fractions $(5 \mu \mathrm{g} /$ lane, except $25 \mu \mathrm{g} /$ lane for homogenates) are marked: $H$, Homogenates; $P 1$, a crude nuclear fraction; $S 1$, a supernatant; $P 2$, a crude membrane fraction; $P 2^{\prime}$, a crude synaptosomal fraction; $L P 1$, a heavy membrane fraction; $L P 2$, a synaptic vesicle fraction; $L S 2$, a cytosolic synaptosomal fraction. $B$, MALS proteins are enriched in the PSD fraction. Rat cerebral cortex homogenate and synaptosomes and isolated PSDs extracted once with $0.5 \%$ Triton X-100 (one triton), twice with $0.5 \%$ Triton X-100 (two triton), or once with $0.5 \%$ Triton X-100 followed by $3 \%$ Sarcosyl (one triton + sarcosyl) were analyzed by immunoblotting with the affinity-purified MALS antibody. Antibodies against PSD-95, NR2B and $\mathrm{K}_{\mathrm{v}} 1.4$, and synaptophysin were used as controls for postsynaptic and presynaptic membrane proteins, respectively. 
A

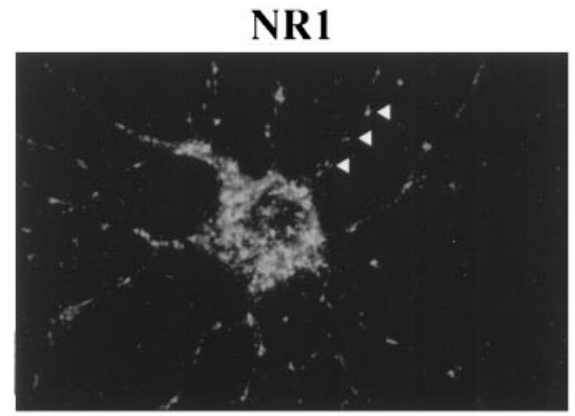

\section{B}

Figure 7. MALS is coclustered with PSD-95 and NR1 in cultured hippocampal neurons. $A$, Hippocampal neurons were double-labeled with NR1 (left) and MALS (right) antibodies. Arrowheads indicate apparent synaptic clusters enriched with both proteins. $B$, Colocalization is also apparent in cultures doublelabeled for PSD-95 (left) and MALS (right) antibodies. All immunolabeling for MALS was eliminated by preabsorption of the MALS antibody with its immunogen (data not shown).
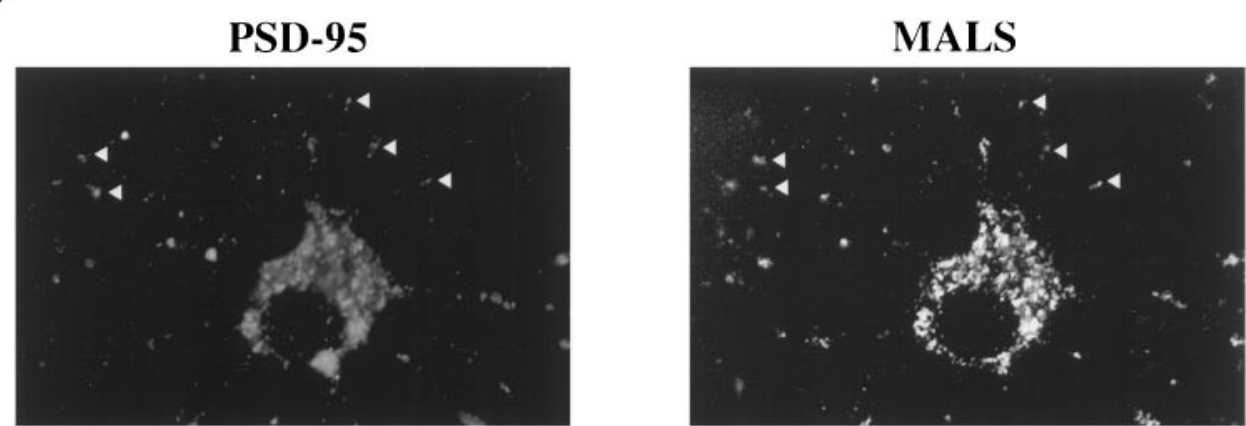

panning. After three rounds of panning, plasmids encoding PDZ domain interacting peptides were sequenced.

\section{RESULTS}

To identify possible mammalian homologs of LIN-7, we searched the Expressed Sequence Tag database and identified three candidates, MALS-1, -2, and -3 (accession numbers AA405216 from human, W75523 from mouse, and AA462021 from mouse, respectively), that show high homology with the C-terminal two thirds of LIN-7, including the PDZ domain. Sequencing of these cDNAs demonstrated that they encode proteins that share $\sim 70 \%$ identity with each other and LIN-7 (Fig. 1). Particularly high homology is found in the PDZ domains, which are $80-90 \%$ identical between MALS-1, -2, and -3. MALS-1 encodes a protein of 233 amino acids (predicted molecular weight, $26 \mathrm{kDa}$ ), MALS-2 a protein of 207 amino acids $(23 \mathrm{kDa})$, and MALS-3 a protein of 197 amino acids $(22 \mathrm{kDa})$. The only major difference between the MALS and LIN-7 is that LIN-7 contains an N-terminal extension of $\sim 100$ amino acids that is not present in the MALS.

To determine whether the MALS are potentially expressed in neurons, we performed Northern blotting on poly $\left(\mathrm{A}^{+}\right)$RNA purified from a variety of rat tissues. We used unique $\left[{ }^{32} \mathrm{P}\right]-$ labeled cDNA probes from the 3' UTR for MALS-1, -2 , and -3 to avoid possible cross-hybridization. We found that each probe recognizes unique bands in poly $\left(\mathrm{A}^{+}\right)$RNA samples from brain (Fig. 2). MALS-1 specifically hybridizes to a band of $1.3 \mathrm{~kb}$, whereas MALS-2 primarily recognizes a band of $0.8 \mathrm{~kb}$ and also to a weaker band at $2.0 \mathrm{~kb}$, and MALS-3 to a band of $4.4 \mathrm{~kb}$. Strikingly, we found that expression of both MALS-1 and MALS-2 is brain-specific. MALS-1 and -2 hybridizing bands are not detectable, even with long exposure, in RNA from heart, kidney, spleen, thymus, or liver. On the other hand, MALS-3 mRNA is most abundantly expressed in kidney, followed by brain and liver, and very faint bands are seen in thymus and heart. MALS-3 is not detectable in spleen.

For analysis of MALS protein expression, we developed an affinity-purified antibody to full-length MALS-2 (see Materials and Methods). Because the PDZ domain is $80-90 \%$ identical between MALS-1, -2 , and -3 , we expected this antibody to react with all three proteins. Western blotting of total brain extracts revealed that the antibody specifically reacts with protein bands of 30 and $25 \mathrm{kDa}$, which closely correspond to the predicted sizes of MALS-1 and MALS-2 and -3, respectively (Fig. 3A). The top 30 $\mathrm{kDa}$ band is almost equally distributed in membrane and soluble fractions of rat brain, and the bottom $25 \mathrm{kDa}$ band is primarily associated with membranes. Because the open reading frames of MALS-1, -2, and -3 are smaller than LIN-7, we considered the possibility that the cDNAs we were analyzing may not be full length. To evaluate this, we cloned the MALS-1, -2 , and -3 cDNAs into a mammalian expression vector (pcDNA3), and expressed them in COS7 cells. Western blotting demonstrates the antibody raised to full-length MALS-2 (designated simply as MALS antibody) recognizes all three MALS proteins. MALS-2 and -3 expressed in transfected cells migrate at $25 \mathrm{kDa}$ and are indistinguishable from the bottom band detected in brain homogenates (Fig. 3A). MALS-1 expressed in COS7 cells migrates at 30 $\mathrm{kDa}$, corresponding to the top band in brain extracts. MALS proteins are not detected in untransfected COS7 cells. To determine whether the top $30 \mathrm{kDa}$ band detected in brain homogenates 
A.

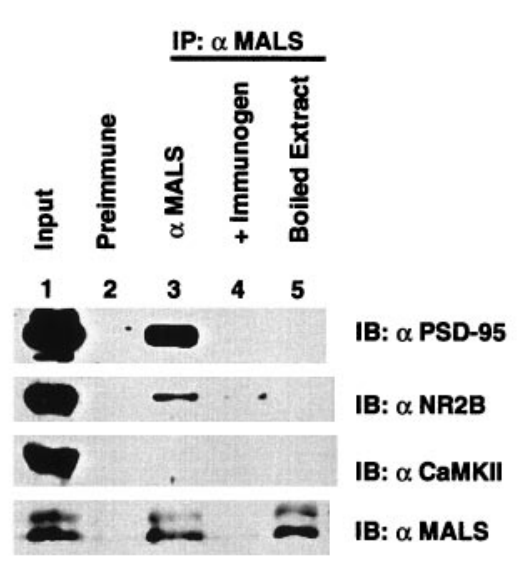

c.

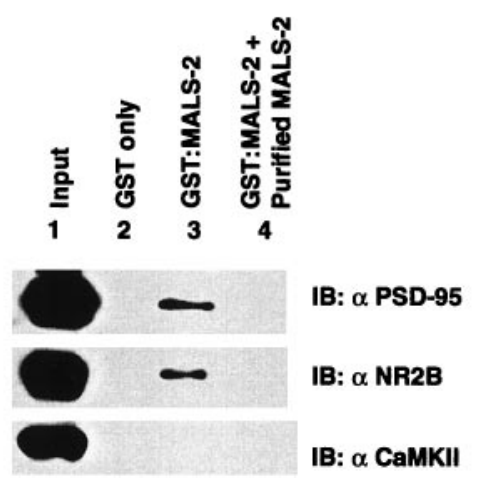

B.

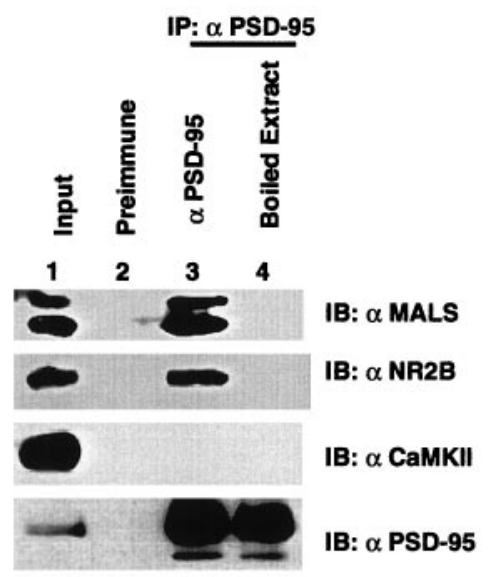

D.

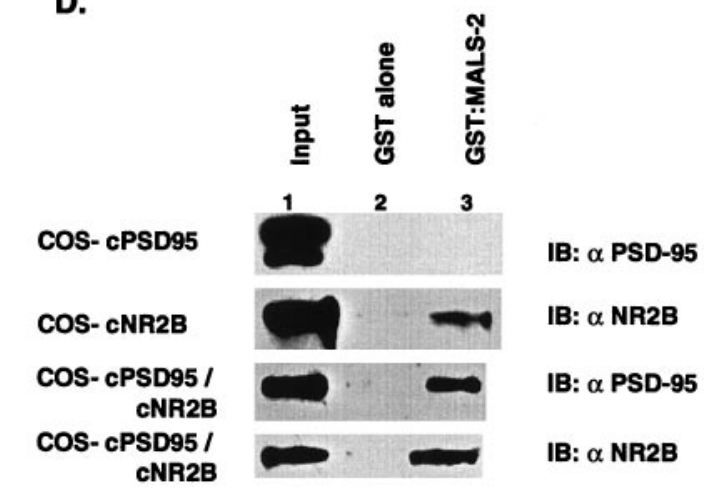

Figure 8. Association of MALS with PSD-95/NR2B. $A$, Coimmunoprecipitation of PSD-95 and NR2B with MALS. Solubilized brain membranes were immunoprecipitated with preimmune serum (lane 2) or with the affinity-purified MALS antibody (lane 3). Coimmunoprecipitation of PSD-95 and NR2B is demonstrated by immunoblotting of these immunoprecipitates. As a control, CaM kinase II $\alpha$ subunit was not present in the immunoprecipitates. When the extracts was presorbed with $50 \mu \mathrm{g}$ of purified GST-MALS-2 (lane 4 ) or boiled with $0.5 \%$ SDS followed by addition of $5 \mathrm{vol}$ of $1 \%$ Triton X-100 (lane 5), PSD-95 and NR2B were not coimmunoprecipitated. Lane 1, Input was $10 \%$ of total protein used for the immunoprecipitation. $B$, Coimmunoprecipitation of and NR2B and MALS with PSD-95. Solubilized brain membranes were immunoprecipitated with preimmune serum (lane 2) or with the PSD-95 antibody (lane 3). Coimmunoprecipitation of MALS and NR2B is demonstrated by immunoblotting of these immunoprecipitates. As a control, CaM kinase II $\alpha$ subunit was not present in the immunoprecipitates. Input, $10 \%$ (lane 1). $C$, Affinity chromatography demonstrates that GST:MALS-2 selectively retains PSD-95 and NR2B from solubilized cerebrocortical membranes (lane 3). Preincubating the extracts with free MALS-2 protein prevented binding of PSD-95 or

NR2B to the column (lane 4). As a control, CaM kinase II $\alpha$ subunit was not retained by the column. $D$, COS7 cells were transfected with expression vectors encoding PSD-95, NR2B, or both. Cell homogenates were pulled-down with GST alone (lane 2) or with GST:MALS-2 (lane 3), and the retained proteins were analyzed by immunoblotting.

corresponds to MALS-1, we developed an antiserum against the relatively unique N-terminal 81 amino acids of MALS-1 (see Materials and Methods). In crude brain extracts, this antibody recognizes a band of $30 \mathrm{kDa}$ and a set of presumably nonspecific bands at $75-80 \mathrm{kDa}$ (Fig. 3B). Immunoprecipitation with the affinity-purified MALS antibody followed by Western blotting with the MALS-1 antibody confirmed that the $30 \mathrm{kDa}$ band corresponds to MALS-1 and that the slower migrating bands are likely to be nonspecific. The predicted molecular masses of MALS-2 and MALS-3 are similar (22 and $23 \mathrm{kDa}$, respectively), suggesting that the bottom band seen in Western blots is likely to contain both MALS-2 and MALS-3.

Western blotting on a variety of tissues confirmed that MALS are expressed at greatest levels in brain (Fig. 4A). In kidney, we detect an intense band of $25 \mathrm{kDa}$, which is explained by the high levels of MALS-3 mRNA that are detected in kidney by Northern blotting (Fig. 2). MALS proteins are not readily detectable in spleen, thymus, liver, lung, skeletal muscle, or pancreas. In heart extracts, we detect low levels of both the 25 and $30 \mathrm{kDa}$ bands (Fig. 4A). These protein bands detected by Western blotting in heart may reflect MALS-3 but may also reflect related MALS proteins that have not been molecularly cloned here.

Western blotting indicated that MALS proteins are ubiquitously expressed in brain and localized in cerebral cortex, cerebellum, hippocampus, olfactory bulb, corpus striatum, and me- dulla. MALS proteins were not detectable in spinal cord (Fig. $4 B)$. The spatial distribution of MALS protein in brain was further evaluated by immunohistochemical staining. Figure $4 C$ represents a dark-field image of a sagittal brain section labeled with MALS antibody. MALS is discretely localized in specific brain, and at high magnification, we find that MALS occurs diffusely throughout the neuropil in the stained brain regions (data not shown). Consistent with Western blotting, MALS protein is found most prominently in cerebellum, cerebral cortex, hippocampus, corpus striatum, and thalamus (Fig. 4C).

To determine whether MALS proteins are likely to be involved primarily in developmental processes, or alternatively if they may also have roles in mature brain, we evaluated expression by Western blotting throughout rat ontogeny. We detected only low levels of the $25 \mathrm{kDa}$ band (MALS-2 and -3) in extracts from E13; the intensity of this $25 \mathrm{kDa}$ band progressively increases during development and reaches maximal levels in the adult. Expression of the $30 \mathrm{kDa}$ band (MALS-1) is not robustly detectable until the second postnatal week, and expression progressively increases thereafter (Fig. 5).

Biochemical fractionation followed by Western blotting was next performed to determine the subcellular localization of the MALS proteins. We found that the MALS were all enriched in a heavy membrane fraction (LP1), and only very low levels of MALS-2 and -3 were found in the synaptic vesicle fraction (LP2). This distribu- 
A.

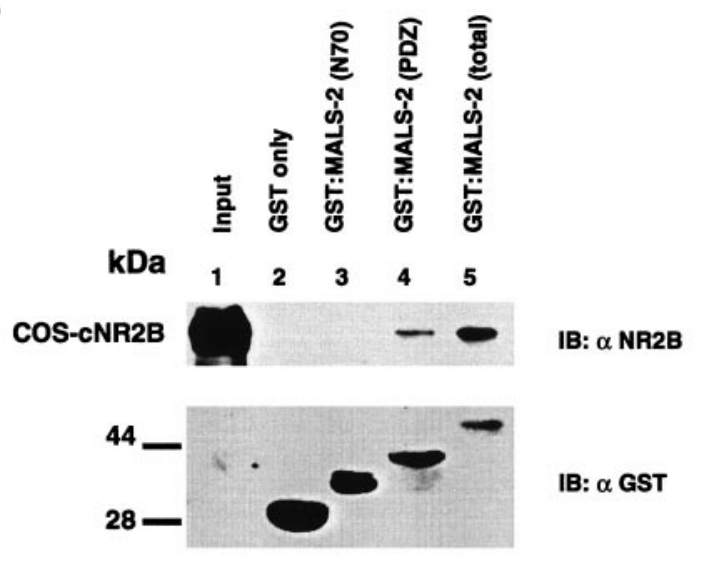

B.

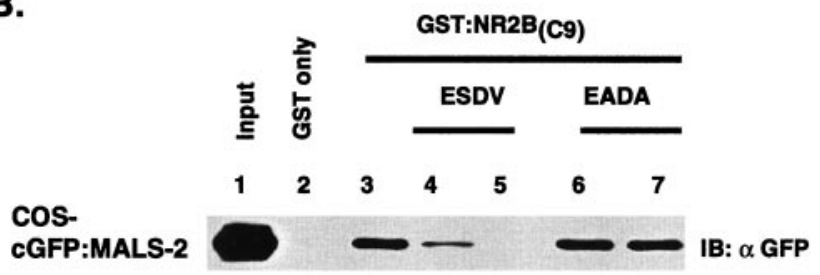

Figure 9. MALS binds to NR2B through a typical PDZ domain/Cterminal tail interaction. $A$, Solubilized extracts from COS7 cells transfected with NR2B (lane 1) were pulled-down with GST alone (lane 2), GST:MALS-2(N70) (lane 3), GST:MALS-2(PDZ) (lane 3) or GST: MALS-2(total) (lane 4). Retained proteins were analyzed by immunoblotting. $B$, Cell homogenates from COS7 cells transfected with GFP: MALS-2 (lane 1) were pulled-down with GST alone (lane 2) or with GST:NR2B(C9) (lanes 3-7). A peptide corresponding to the C-terminal nine amino acids of NR2B (ESDV) was added to the binding reaction at 5 (lane 4 ) or 50 (lane 5) $\mu \mathrm{M}$. A similar peptide in which the last four amino acids were replaced with EADA was added into the binding reaction at 5 (lane 6) or 50 (lane 7) $\mu \mathrm{M}$. Retained GFP:MALS-2 was detected by immunoblotting with a GFP antibody.

tion is similar to that of PSD-95 and NR2B, postsynaptic markers. In contrast, synaptophysin, a synaptic vesicle marker, is appropriately concentrated in LP2, and neurofilament-H, a nonsynaptic protein, is not enriched in the synaptosomal preparations (Fig. $6 A$ ). In a separate procedure, synaptosomal fractions were prepared by discontinuous sucrose gradient centrifugation. We found a considerable enrichment of MALS proteins in synaptosomes. The synaptosome-associated MALS was further extracted to prepare PSD fractions (Cho et al., 1992). We found that MALS proteins are highly resistant to extraction with the nonionic detergents Triton X-100 and Sarcosyl (Fig. 6B). This behavior is similar to that of PSD-95 and NR2B, biochemical markers for the PSD fraction (Cho et al., 1992). To test the specificity of the PSD fractionation, the same blot was reprobed for $\mathrm{K}_{\mathrm{v}} 1.4$ and synaptophysin, presynaptic membrane proteins (Sheng et al., 1992). As expected, we found that $\mathrm{K}_{\mathrm{v}} 1.4$ and synaptophysin are efficiently extracted with Triton X-100 and are not enriched in the PSD fractions (Fig. 6B).

To further evaluate the cellular localization of MALS, we performed immunofluorescent labeling of cultured hippocampal neurons using the MALS antibody. MALS was expressed in a somatodendritic pattern in cultured neurons. Along neuronal processes, immunoreactivity for MALS is punctate, suggesting that MALS may be localized at synapses (Fig. 7). To evaluate this, we double-labeled cultures for MALS and PSD-95 or NR1. Previous characterization of these cultures demonstrates that punctate dendritic labeling for PSD-95 and NR1 occurs at synapses as the puncta colocalize with synaptophysin (Torres et al., 1998). We found that most of the punctate dendritic clusters of MALS immunofluorescence were colocalized with NR1 and PSD-95 along the neuronal processes at putative synaptic sites (Fig. 7A,B).

Because MALS proteins copurify with PSD-95 in brain fractionations and are colocalized with PSD-95 at synapses, we asked whether these proteins occur together in a protein complex. To determine whether MALS associate with PSD-95, we performed immunoprecipitation analysis (Fig. 8A). We found that our antibody to MALS readily immunoprecipitates PSD-95 and NR2B from solubilized membranes of rat cerebral cortex. In contrast, CaM kinase II $\alpha$ subunit, which is also enriched in PSD, does not coimmunoprecipitated with MALS. Controls with the preimmune MALS antiserum or MALS-antiserum that was presorbed with immunogen block the coimmunoprecipitation, confirming the selectivity of the association. In brain extracts that were initially boiled in $0.5 \%$ SDS, MALS are still immunoprecipitated, although PSD-95/NR2B are not, indicating that coprecipitation requires native protein interactions (Fig. $8 A$ ). Because the MALS antibody cross-reacts with all three MALS proteins, it was not clear which protein(s) are associate with the PSD-95/ NMDA receptor complexes. To address this question, we probed PSD-95 immunoprecipitates for the presence of MALS proteins. Both the 25 and $30 \mathrm{kDa}$ bands are detected in the PSD-95 immunoprecipitates, suggesting that multiple MALS proteins associate with PSD-95/NMDA receptor complexes. To evaluate these interactions in a different way, we performed affinity chromatography or pull-down assays using a fusion protein of MALS-2 linked to GST. Solubilized cerebrocortical membranes were incubated with either GST:MALS-2 or GST alone immobilized to glutathione-Sepharose beads. After this binding reaction, columns were washed extensively, and retained proteins were eluted with SDS. Western blotting indicated that PSD-95 and NR2B are selectively retained by the GST:MALS-2 beads (Fig. $8 C$ ).

These associations detected among proteins from brain extracts suggested a possible direct interaction of MALS with either NR2B or PSD-95. To address this, we investigated binding of MALS-2 to PSD-95 or NR2B expressed in transfected COS7 cells, which do not otherwise express PSD-95 or NR2B. We first performed pull-down assays with GST:MALS-2 on extracts from cells individually transfected with either PSD-95 or NR2B. We found that the GST:MALS-2 fusion does not directly bind to PSD-95 but does bind to NR2B. We performed similar pull-down assays on extracts from cells cotransfected with PSD-95 and NR2B. From these cotransfections, we found that both PSD-95 and NR2B avidly bind to the MALS-2 fusion protein column, suggesting formation of a tight ternary complex (Fig. 8D).

The direct binding of MALS to NR2B, which terminates in E-S-D-V, is reminiscent of PDZ domain interactions. To define the regions of MALS and NR2B that are involved in the interaction, we prepared GST fusion proteins representing isolated regions of MALS-2 and NR2B. A GST fusion containing only the PDZ domain of MALS-2 [GST:MALS-2(PDZ)] binds NR2B expressed in COS7 cells, whereas an MALS-2 construct containing only the unique $\mathrm{N}$-terminal region [GST:MALS2(N70)] is inactive (Fig. 9A). Also, a GST fusion containing only 


\begin{tabular}{|c|c|c|c|}
\hline Clone no. & Sequence & Clone no. & Sequence \\
\hline $\mathrm{W}-1$ & GGGVSRIGFGCGRRCYRL & $\mathrm{W}-11$ & GGGVFEEVYAFESLETAL \\
\hline $\mathrm{W}-2$ & $* * * * * * * * *$ GGGVHETRV & $\mathrm{W}-12$ & GGGVFRMPLGFEQLETRV \\
\hline $\mathrm{W}-3$ & $* * * * * * * *$ GGGELWAETS & $\mathrm{W}-13$ & GGGTRRGEWRSFRVESRL \\
\hline W-4 & GGGLAGGAWNLKRHGTRV & W-14 & GGGCGSRQSVVRGAESRV \\
\hline $\mathrm{W}-5$ & $* * * * * * *$ GGGTLGRETSV & $\mathrm{W}-15$ & GGGAWNRPEPGEWNETRI \\
\hline W-6 & GGGLHMRGYIQGYRITGV & $\mathrm{W}-16$ & GGGRLSIRDYVRSGETAL \\
\hline $\mathrm{W}-7$ & $* * * * * * *$ GGGAEWMESYI & $\mathrm{W}-17$ & GGGRRSLGSDEAWWETRV \\
\hline $\mathrm{W}-8$ & GGGSRRVQADWSRFETRF & $\mathrm{W}-18$ & GGGNHSAESYVMTRESQL \\
\hline W-9 & GGGTWQEHGGCIMGETSL & W-19 & GGGMHNESAAVCLRETGV \\
\hline \multirow[t]{2}{*}{$\mathrm{W}-10$} & $* * * * * * * * *$ GGGMRETTL & $\mathrm{W}-20$ & $* * * * * * * * *$ GGGMMETSV \\
\hline & & $\mathrm{W}-21$ & **GGGYESAWAGLTESRV \\
\hline
\end{tabular}

Sequence alignment of 21 independent MALS binding peptides. The deduced amino acid sequences of 21 independent clones were obtained and aligned according to the first stop codon. The library template is GGG-XXXXXXXXXXXXXXX.

the C-terminal nine amino acids of NR2B [GST:NR2B(C9)] binds to a GFP:MALS-2 protein expressed in COS7 cells. Binding of MALS-2 to the C terminus of NR2B is potently blocked by a peptide corresponding to the final nine amino acids of NR2B. This effect is specific because a control 9-mer peptide in which the critical serine and valine are mutated to alanine does not disrupt the interaction (Fig. 9B).

To evaluate binding properties for the PDZ domain of MALS, we took advantage of a peptide display strategy and screened billions of distinct peptides to select sequences that specifically bind to the PDZ domain of MALS-2. We have previously used this in vitro selection strategy to determine optimal peptides for binding to PDZ domains of nNOS and PSD-95 (Stricker et al., 1997). For this technique, a GST fusion protein of full-length MALS-2 was incubated with a 15-mer LacI library of complexity $1.3 \times 10^{10}$. After three rounds of panning, the binding specificity of the isolated clones was determined by ELISA. The sequences of 21 interacting peptides were determined (Table. 1). The preferred C-terminal peptide for interaction with MALS-2 is E-T/ $\mathrm{S}-\mathrm{R} / \mathrm{X}-\mathrm{V} / \mathrm{L} / \mathrm{I} / \mathrm{F}$ (Fig. 10), which matches the $\mathrm{C}$ terminus of NR2B. Overall, this selectivity is similar to that seen for PDZ domains for PSD-95, which best interact with proteins terminating E-T/S-X-V/I (Songyang et al., 1997; Stricker et al., 1997). The differences are that MALS-2 tolerates leucine and phenylalanine at the 0 position and that MALS-2 has a significant preference for $\mathrm{R}$ at the -1 position (Fig. 10). These results also explain the observed interaction between MALS and NR2B and suggest that the PDZ domain of MALS likely also binds to other ion channels at the synapse.

\section{DISCUSSION}

The primary finding of this study is the identification of MALS-1, -2 , and -3 , a family of mammalian homologs of C. elegans LIN-7 that are enriched at the postsynaptic density of central synapses. Similar to LIN-7 in C. elegans, the MALS are small proteins that each contain a $\mathrm{C}$-terminal PDZ domain and a short $\mathrm{N}$-terminal sequence (Simske et al., 1996). The amino acid sequences of this family of proteins are remarkably conserved between mammals and nematodes (65-70\% identical) and suggest the functional roles for these proteins are similar. In C. elegans, however, LIN-7 occurs in epithelial cells rather than in neurons, and LIN-7 mutants have a vulvaless phenotype rather than a neuronal phenotype (Simske et al., 1996). In vulval precursor epithelial cells, LIN-7 localizes a receptor tyrosine kinase receptor to the baso- lateral cell junction (Simske et al., 1996). By analogy, we suspect that the MALS binds to neurotransmitter receptors in brain and targets them to the PSD. Indeed, we find that the PDZ domain of MALS can bind the C terminus of NR2B and that MALS occur together with this glutamate receptor in the PSD.

The synaptic localization of MALS-1, -2 , and -3 in neurons compared with the basolateral localization of LIN-7 in C. elegans epithelial vulval precursor cells is consistent with studies that have identified structural analogies between epithelial tight junctions and neuronal synapses (Cho et al., 1992; Bredt, 1998). For example, high levels of the PSD-95/SAP-90 family of MAGUK proteins at neuronal synapses (Cho et al., 1992; Kistner et al., 1993; Lahey et al., 1994; Guan et al., 1996) is paralleled by ubiquitous expression of related MAGUKs, such as zona occludens-1, -2, and -3, at epithelial tight junctions (Woods and Bryant, 1991; Willott et al., 1993; Jesaitis and Goodenough, 1994). In addition to these structural similarities, neurons and epithelial cells share certain common mechanisms for subcellular sorting of membrane proteins. Seminal studies by Dotti and Simons (1990) have shown that some (but not all) proteins that occur at the basolateral domain of epithelial cells are targeted to neuronal dendrites. Furthermore, the same cytosolic sequences that determine basolateral localization of epithelial membrane proteins can mediate dendritic sorting of certain neuronal proteins (Jareb and Banker, 1998). Because LIN-7 plays a primary role in localizing LET-23, a transmembrane receptor to the basolateral membrane of vulval precursors (Simske et al., 1996), we suspect that MALS proteins may contribute to dendritic and postsynaptic targeting of neuronal receptors. In support of this notion, a very recent study showed that lin-10 is essential for postsynaptic targeting of a glutamate receptor in C. elegans interneurons (Rongo et al., 1998). Although lin-7 was specifically not required for postsynaptic targeting of the glutamate receptor (Rongo et al., 1998), it is possible that a LIN-7 isoform in $C$. elegans neurons cooperates with LIN-10 to mediate receptor sorting.

To help identify proteins that might be synaptically targeted by MALS, we determined the binding specificity of the PDZ domain. This analysis demonstrated that the PDZ domain of MALS-2 has a binding preference for polypeptides terminating in $\mathrm{E}-\mathrm{T} / \mathrm{S}-\mathrm{R} / \mathrm{X}-\mathrm{V} / \mathrm{I} / \mathrm{L}$, which matches the $\mathrm{C}$ terminus of $\mathrm{NR} 2 \mathrm{~B}$. This generally conforms to the type I consensus for PDZ domains (Songyang et al., 1997). Interestingly, this generally matches the C terminus of LET-23 (Q-T-C-L) and is consistent with the ob- 


\section{GST:MALS-2}

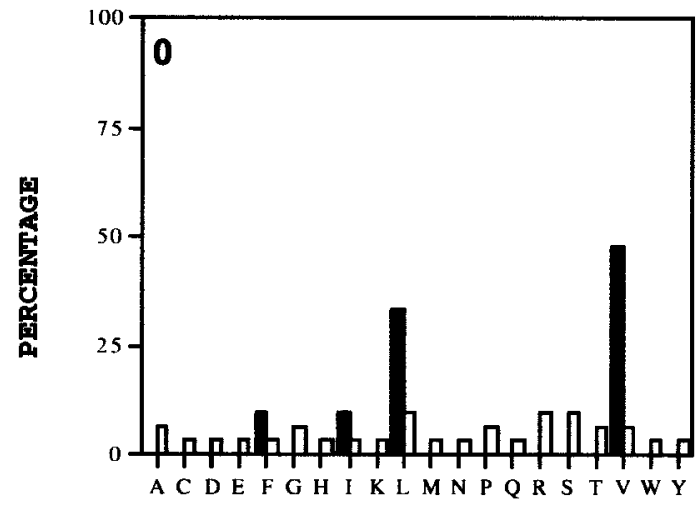

AMINO ACID

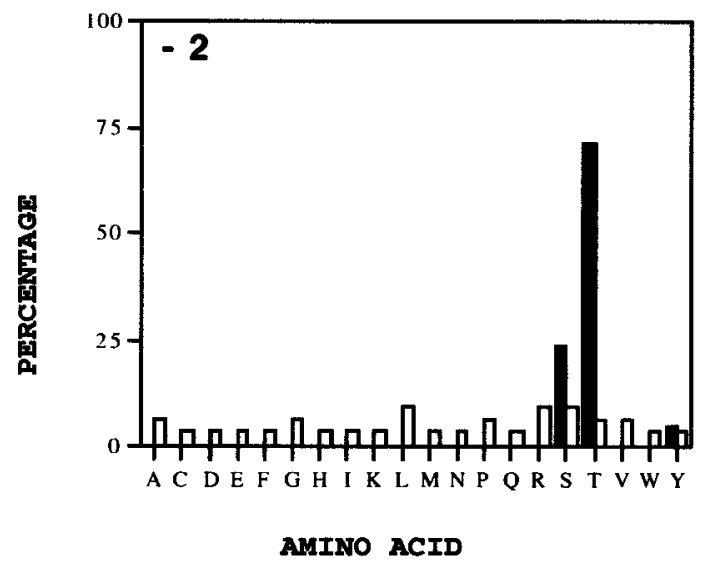

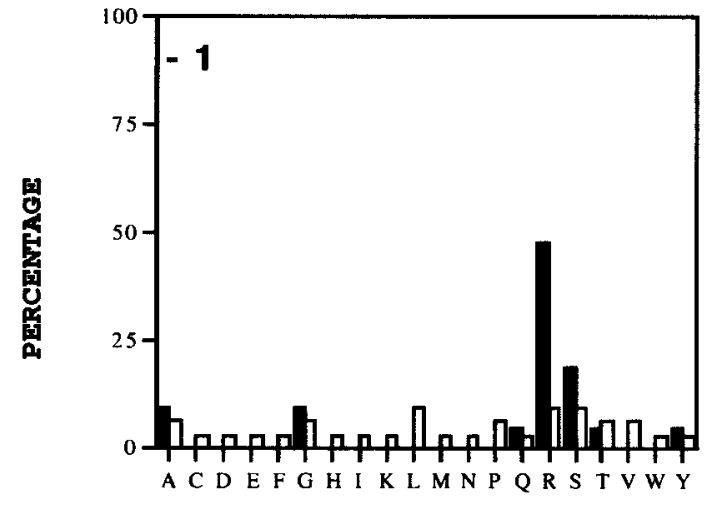

AMINO ACID

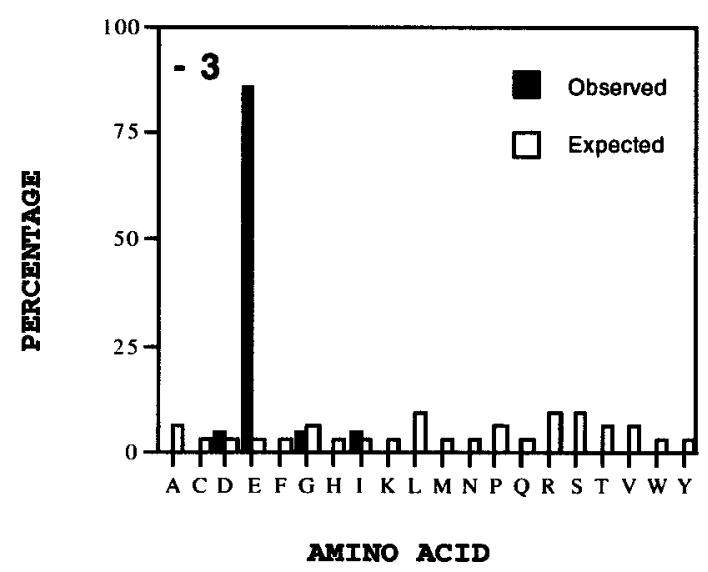

Figure 10. The PDZ domain of MALS-2 binds peptides terminating in E-T/S-R/X-V/I/L. Normalized amino acid abundance of the final four residues from 21 independent MALS-2 binding peptides (black bars) is compared with codon frequency in the original library (white bars).

served interaction between LIN-7 and LET-23 (Hoskins et al., 1996; Kaech et al., 1998). Our searches of the database indicated that erbB4, but not other epidermal growth factor receptor tyrosine kinases, terminates with a sequence (N-T-T-V) that might bind the MALS. To detect possible interaction, we performed affinity chromatography of brain extracts on a column of GST: MALS-2 fusion protein and attempted coimmunoprecipitation of erbB4 with MALS from brain extracts. Under a variety of conditions, we were unable to detect association of MALS and erbB4 by these methods (data not shown). This lack of binding is likely attributable to the fact that MALS prefers C-terminal peptides containing glutamate at the -3 position (Fig. 9) but that erbB4 has asparagine at this position. On the other hand, numerous proteins in the PSD, including NMDA receptors and certain $\mathrm{K}^{+}$channels (Sheng, 1996; Kornau et al., 1997), contain more precisely the C-terminal consensus E-T/S-R/X-V/I/L that determines optimal binding to MALS.

Although we propose a role for MALS in regulating NMDA receptor sorting, it is uncertain how MALS proteins themselves dock to synaptic membranes. The prototypical synaptic PDZ protein PSD-95 is targeted to cell membranes through N-terminal palmitoylation (Topinka and Bredt, 1998). MALS proteins, however, lack $\mathrm{N}$-terminal cysteines or other consensus sequences for lipid modification. It therefore seems more likely that MALS proteins bind to integral or peripheral membrane proteins of the PSD. Although MALS proteins coimmunoprecipitate with PSD95, we could not detect direct interaction between MALS and PSD-95 and do not favor PSD-95 as a direct anchor for MALS at the PSD. Other likely candidates for targeting MALS to the PSD are the mammalian homologs of LIN-2 (CASK) (Hata et al., 1996) and LIN-10 (Mint/X11) (Borg et al., 1996; Okamoto and Südhof, 1997). Mutations of lin-2 and lin-10 in C. elegans disrupt basolateral targeting of LET-23 (Simske et al., 1996; Kaech et al., 1998), suggesting a possible role for these proteins in targeting of LIN-7. Indeed, very recent studies demonstrate that LIN-7 directly binds to LIN-2, which itself directly associates with LIN-10 (Kaech et al., 1998). This work shows the conserved sequence just $\mathrm{N}$ terminal to the PDZ domain of LIN-7 mediates binding to LIN-2 (Kaech et al., 1998). This ternary complex has also been isolated from mammalian brain such that CASK (LIN-2) binds to both Mint-1 (LIN-10) and the Velis (vertebrate homologs of LIN-7), which are apparently identical to the MALS described here (Butz et al., 1998). This ternary complex of CASK/Mint-1/ Velis (MALS) is proposed to occur primarily at presynaptic terminals in association with neurexin (Butz et al., 1998). It is not yet known, however, whether this complex might also occur at the PSD. Future anatomical and biochemical studies are needed to address this issue. 
Our finding that MALS is already expressed in brain at E13, an early point of neurogenesis, fits with the developmental function of LIN-7 in vulval development. By analogy, we suspect that MALS proteins may help localize receptors that are important for synaptogenesis. Although mechanisms for synaptic development in brain are unknown, postsynaptic differentiation of the neuromuscular junction requires the activity of a muscle-specific receptor tyrosine kinase, MuSK (DeChiara et al., 1996; Glass et al., 1996). The functional equivalent to MuSK in brain has not yet been identified, but several families of receptor tyrosine kinases occur in developing brain. The largest family of such molecules comprises the ephrin receptors (Flanagan and Vanderhaeghen, 1998). Recent studies have shown that many of the ephrin family receptors, which terminate in $\mathrm{V}-\mathrm{X}-\mathrm{V}$, are synaptically clustered through interactions with class II PDZ domain-containing proteins (Torres et al., 1998). Although the PDZ domain of MALS is unlikely to interact specifically with ephrin receptors, it will be important to determine whether MALS proteins mediate synaptic localization of other neuronal receptor tyrosine kinases.

Whereas MALS expression is first detectable in developing brain, highest expression levels are found in the adult, suggesting important roles for MALS protein in brain function. Indeed, many processes that are important for brain development remain active in the adult brain to mediate neuronal plasticity necessary for learning and memory. Through interactions with NMDA receptors and other synaptic proteins, MALS may regulate aspects of synaptic plasticity in adult brain. To decisively determine the role of MALS proteins in synaptic development and physiology, it will be important to delete the function of the MALS by knock-out and dominant negative approaches.

\section{REFERENCES}

Apperson ML, Moon IS, Kennedy MB (1996) Characterization of densin-180, a new brain-specific synaptic protein of the $O$-sialoglycoprotein family. J Neurosci 16:6839-6852.

Borg JP, Ooi J, Levy E, Margolis B (1996) The phosphotyrosine interaction domains of X11 and FE65 bind to distinct sites on the YENPTY motif of amyloid precursor protein. Mol Cell Biol 16:6229-6241.

Bredt DS (1998) Sorting out genes that regulate epithelial and neuronal polarity. Cell 94:691-694.

Brenman JE, Chao DS, Xia H, Aldape K, Bredt DS (1995) Nitric oxide synthase complexed with dystrophin and absent from skeletal muscle sarcolemma in Duchenne muscular dystrophy. Cell 82:743-752.

Brenman JE, Chao DS, Gee SH, McGee AW, Craven SE, Santillano DR, Huang F, Xia H, Peters MF, Froehner SC, Bredt DS (1996) Interaction of nitric oxide synthase with the postsynaptic density protein PSD-95 and $\alpha-1$ syntrophin mediated by PDZ motifs. Cell 84:757-767.

Butz S, Okamoto M, and Südhof TC (1998) A tripartite protein complex with the potential to couple synaptic vesicle exocytosis to cell adhesion in brain. Cell 94:773-782.

Cho KO, Hunt CA, Kennedy MB (1992) The rat brain postsynaptic density fraction contains a homolog of the Drosophila discs-large tumor suppressor protein. Neuron 9:929-942.

Craven SE, Bredt DS (1998) PDZ proteins organize synaptic signaling pathways. Cell 93:495-498.

DeChiara TM, Bowen DC, Valenzuela DM, Simmons MV, Poueymirou WT, Thomas S, Kinetz E, Compton DL, Rojas E, Park JS, Smith C, DiStefano PS, Glass DJ, Burden SJ, Yancopoulos GD (1996) The receptor tyrosine kinase MuSK is required for neuromuscular junction formation in vivo. Cell 85:501-512.

Dotti CG, Simons K (1990) Polarized sorting of viral glycoproteins to the axon and dendrites of hippocampal neurons in culture. Cell 62:63-72.

Doyle DA, Lee A, Lewis J, Kim E, Sheng M, MacKinnon R (1996) Crystal structures of a complexed and peptide-free membrane proteinbinding domain: molecular basis of peptide recognition by PDZ. Cell 85:1067-1076.

Flanagan JG, Vanderhaeghen P (1998) The ephrins and Eph receptors in neural development. Annu Rev Neurosci 21:309-345.
Glass DJ, Bowen DC, Stitt TN, Radziejewski C, Bruno J, Ryan TE, Gies DR, Shah S, Mattson K, Burden SJ, Distefano PS, Valenzuela DM, DeChiara TM, Yancopoulos GD (1996) Agrin acts via a MuSK receptor complex. Cell 85:513-524.

Guan B, Hartmann B, Kho YH, Gorczyca M, Budnik V (1996) The Drosophila tumor suppressor gene, dlg, is involved in structural plasticity at a glutamatergic synapse. Curr Biol 6:695-706.

Hata Y, Butz S, Sudhof TC (1996) CASK: a novel dlg/PSD95 homolog with an $\mathrm{N}$-terminal calmodulin-dependent protein kinase domain identified by interaction with neurexins. J Neurosci 16:2488-2494.

Hoskins R, Hajnal AF, Harp SA, Kim SK (1996) The C. elegans vulval induction gene lin-2 encodes a member of the MAGUK family of cell junction proteins. Development 122:97-111.

Jareb M, Banker G (1998) The polarized sorting of membrane proteins expressed in cultured hippocampal neurons using viral vectors. Neuron 20:855-867.

Jesaitis LA, Goodenough DA (1994) Molecular characterization and tissue distribution of $\mathrm{ZO}-2$, a tight junction protein homologous to $\mathrm{ZO}-1$ and the Drosophila discs-large tumor suppressor protein. J Cell Biol 124:949-961.

Kaech SM, Whitfield CW, Kim SK (1998) The LIN-2/LIN-7/LIN-10 complex mediates basolateral membrane localization of the C. elegans EGF receptor LET-23 in vulval epithelial cells. Cell 94:761-771.

Kistner U, Wenzel BM, Veh RW, Cases-Langhoff C, Garner AM, Appeltauer U, Voss B, Gundelfinger ED, Garner CC (1993) SAP90, a rat presynaptic protein related to the product of the Drosophila tumor suppressor gene dlg-A. J Biol Chem 268:4580-4583.

Kornau H-C, Schenker LT, Kennedy MB, Seeburg PH (1995) Domain interaction between NMDA receptor subunits and the postsynaptic density protein PSD-95. Science 269:1737-1740.

Kornau H-C, Seeburg PH, Kennedy MB (1997) Interaction of ion channels and receptors with PDZ domains. Curr Opin Neurobiol 7:368-373.

Lahey T, Gorczyca M, Jia XX, Budnik V (1994) The Drosophila tumor suppressor gene dlg is required for normal synaptic bouton structure. Neuron 13:823-835.

Li XJ, Sharp AH, Li SH, Dawson TM, Snyder SH, Ross CA (1996) Huntingtin-associated protein (HAP1): discrete neuronal localizations in the brain resemble those of neuronal nitric oxide synthase. Proc Natl Acad Sci USA 93:4839-4844.

Okamoto M, Südhof TC (1997) Mints, Munc18-interacting proteins in synaptic vesicle exocytosis. J Biol Chem 272:31459-31464.

Rongo C, Whitfield CW, Rodal A, Kim SK, Kaplan JM (1998) LIN-10 is a shared component of the polarized protein localization pathways in neurons and epithelia. Cell 94:751-759.

Sheng M (1996) PDZs and receptor/channel clustering: rounding up the latest suspects. Neuron 17:575-578.

Sheng M, Tsaur ML, Jan YN, Jan LY (1992) Subcellular segregation of two A-type $\mathrm{K}^{+}$channel proteins in rat central neurons. Neuron 9:271-284.

Simske JS, Kaech SM, Harp SA, Kim SK (1996) LET-23 receptor localization by the cell junction protein LIN-7 during C. elegans vulval induction. Cell 85:195-204.

Songyang Z, Fanning AS, Fu C, Xu J, Marfatia SM, Chishti AH, Crompton A, Chan AC, Anderson JM, Cantley LC (1997) Recognition of unique carboxyl-terminal motifs by distinct PDZ domains. Science 275:73-77.

Stricker NL, Christopherson KS, Yi BA, Schatz PJ, Raab RW, Dawes G, Bassett Jr DE, Bredt DS, Li M (1997) PDZ domain of neuronal nitric oxide synthase recognizes novel $\mathrm{C}$-terminal peptide sequences as determined by in vitro selection. Nat Biotechnol 15:336-342.

Tejedor FJ, Bokhari A, Rogero O, Gorczyca M, Zhang J, Kim E, Sheng M, Budnik V (1997) Essential role for dlg in synaptic clustering of Shaker $\mathrm{K}^{+}$channels in vivo. J Neurosci 17:152-159.

Topinka JR, Bredt DS (1998) N-terminal palmitoylation of PSD-95 regulates association with cell membranes and interaction with $\mathrm{K}^{+}$channel, Kv1.4. Neuron 20:125-134.

Torres R, Firestein BL, Staudinger J, Dong H, Olson EN, Huganir RL, Bredt DS, Gale NW, Yancopoulos GD (1998) PDZ proteins bind, cluster and synaptically co-localize with Eph receptors and their ligands, the ephrins. Neuron 21:1453-1463.

Willott E, Balda MS, Fanning AS, Jameson B, Van Itallie C, Anderson JM (1993) The tight junction protein ZO-1 is homologous to the Drosophila discs-large tumor suppressor protein of septate junctions. Proc Natl Acad Sci USA 90:7834-7838.

Woods DF, Bryant PJ (1991) The discs-large tumor suppressor gene of Drosophila encodes a guanylate kinase homolog localized at septate junctions. Cell 66:451-464. 